\title{
Ethanol Production from Extruded Thermoplastic Maize Meal by High Gravity Fermentation with Zymomonas mobilis
}

\author{
Mayeli Peralta-Contreras, ${ }^{1}$ Edna Aguilar-Zamarripa, ${ }^{1}$ Esther Pérez-Carrillo, ${ }^{1}$ \\ Erandi Escamilla-García, ${ }^{2}$ and Sergio Othon Serna-Saldívar ${ }^{1}$ \\ ${ }^{1}$ Centro de Biotecnología FEMSA, Tecnológico de Monterrey, Avenida Eugenio Garza Sada 2501 Sur, Col. Tecnológico, \\ 64849 Monterrey, NL, Mexico \\ ${ }^{2}$ Centro de Investigación y Desarrollo en Ciencias de la Salud/UOIE, Universidad Autónoma de Nuevo León (UANL), \\ Avenida Carlos Canseco s/n con Avenida Gonzalitos, Mitras Centro, 64460 Monterrey, NL, Mexico
}

Correspondence should be addressed to Esther Pérez-Carrillo; perez.carrillo@itesm.mx

Received 26 August 2014; Accepted 25 September 2014; Published 3 November 2014

Academic Editor: Triantafyllos Roukas

Copyright (c) 2014 Mayeli Peralta-Contreras et al. This is an open access article distributed under the Creative Commons Attribution License, which permits unrestricted use, distribution, and reproduction in any medium, provided the original work is properly cited.

A comparative study of extruded and ground maize meals as raw materials for the production of regular $\left(12^{\circ} \mathrm{P}\right)$ and high gravity $\left(20^{\circ} \mathrm{P}\right)$ worts was devised. Extruded water solubility index (WSI) was higher (9.8 percentage units) and crude fat was lower (2.64 percentage units) compared to ground maize. Free-amino nitrogen compounds (FAN), pH, and glucose were evaluated in regular and high gravity worts produced from ground or extruded maize. Extrusion improved glucose content and ethanol yield. In $20^{\circ} \mathrm{P}$ mashes, extrusion is enhanced by $2.14 \%$ initial glucose compared with regular ground mashes. The $12^{\circ} \mathrm{P}$ and $20^{\circ} \mathrm{P}$ extruded treatments averaged $12.2 \%$ and $8.4 \%$ higher ethanol, respectively, compared to the uncooked counterpart. The $20^{\circ} \mathrm{P}$ worts fermented with Zymomonas mobilis produced $9.56 \%$ more ethanol than the $12^{\circ} \mathrm{P}$ counterpart. The results show that the combination of extrusion and fermentation of $20^{\circ} \mathrm{P}$ worts improved ethanol yield per $\mathrm{kg}$ flour until $20.93 \%$. This pretreatment stimulates $Z$. mobilis fermentation efficiency.

\section{Introduction}

Bioethanol is produced from the fermentation of sugars obtained from biomass. Bioethanol feedstock can contain either sucrose (e.g., sugarcane, sugar beet) or starch (e.g., corn, wheat) or be a lignocellulosic material (e.g., sugarcane bagasse, wood, and straw). Corn and sugarcane are the feedstock used in the US and in Brazil, respectively, which are the largest ethanol producers in the world [1]. Although maize grain has the highest yield for ethanol conversion $(360$ liters of ethanol per metric ton) and it is considered the majority source of the fuel ethanol industry in the United States, technological innovations are required in order to provide faster and highest conversion yields of carbohydrates to ethanol [2-4].

There is growing interest to develop several new technologies, especially through mechanical, chemical, and biological processes to optimize ethanol produced from maize $[5,6]$. An interesting approach is the implementation of thermoplastic extrusion, because it modifies starch to dextrose and lowers energy needs for high pressure steam. This continuous cooking process pregelatinizes the starch using a combination of moisture, pressure, heat, and mechanical stress [7-9]. Even though the temperature required to complete starch gelatinization is between $80^{\circ} \mathrm{C}$ and $100^{\circ} \mathrm{C}$, the extruder screw speed causes an important pressure increase and the rupture of the food matrix. Extrusion technology allows quick gelatinization using less processing water and short residence time compared to the traditional liquefaction process which could reduce energy and costs. Maize extrudates can be fully and efficiently hydrolyzed in order to elevate the bioavailability of potential sugars $[10,11]$. Therefore, the physical and chemical characteristics after the extrusion process have been an important research topic. Carvalho et al. observed 
on extruded cereal grits changes in particle size distribution which modified the characteristics of the resulting expanded products [11]. On the other hand, Naidu et al. mentioned that the particle size distribution from uncooked cereal meals may affect the starch digestion which could impact the enzymatic hydrolysis and changes during saccharification and fermentation [12].

Fermentation based on Saccharomyces cerevisiae has been widely used for the bioethanol and alcohol beverage industries. However, S. cerevisiae presents some disadvantages at higher sugar or ethanol concentrations reducing yeast viability and ethanol yield [13]. The research of ethanol-tolerant microorganisms has been highly relevant for fermentation processes. Among them, Z. mobilis could produce a $97 \%$ theoretical yield of ethanol to glucose, while S. cerevisiae only can achieve 90-93\% [13$15]$.

Z. mobilis has positioned as an ethalogenic organism with potential industrial application because it possesses a metabolism that yields a molecule of ATP per glucose molecule, and produces less biomass. Also, these strengths include the conversion of $95 \%$ of glucose into ethanol (with a minor percentage of $3 \%$ of incorporation into its cellular mass), elevated growth rates, tolerance to acidic conditions, no requirement for oxygenated conditions, cost reduction in the aeration, elevated osmotolerance in a substrate/product ratio (because the hopanoids act as stabilizers to the cellular membrane), and reduced nutritional requirements [16]. Moreau et al. have studied ethanol tolerance exhibited by this bacterium based on the hopanoids and other membrane lipids [17].

In characterization studies, the initial sugar concentration is an important parameter for Z. mobilis growth; however, high glucose concentrations could induce inhibition ethanol production [18]. High gravity (HG) fermentation technology is used for industrial scale production of bioethanol. HG technology is defined as "the preparation and fermentation to completion of mashes containing $20 \mathrm{~g}$ dissolved solids per $100 \mathrm{~g}$ mash." Its benefits include a decrease in process water requirements and energy costs and increased productivity and ethanol concentration in the products without extra capital expenditure [13]. On the other hand, S. cerevisiae suffers stress by environmental factors, such as nitrogen limitation, which induces a decline in fermentation activity noted during the early stages of fermentations and can cause sluggish or stuck fermentations [17].

The aim of the current work was to study the effect of thermoplastic extrusion and to propose high gravity ethanol fermentation with Z. mobilis ATCC 31823, comparing $12^{\circ} \mathrm{P}$ and $20^{\circ} \mathrm{P}$ worts. Despite the importance of the high gravity worts, no previous reports have explored the effects of extruded and ground corn meals with this particular fermentation bacterium.

The pretreatment technology (dry milling and extrusion) and elevated concentration of solids $\left(12^{\circ} \mathrm{P}\right.$ or $\left.20^{\circ} \mathrm{P}\right)$ were compared by the fermentation samples during $72 \mathrm{~h}$. Also, the $\mathrm{pH},{ }^{\circ}$ Plato, glucose consumption, free-amino nitrogen compounds (FAN), and ethanol concentrations were determined in the present study.

\section{Materials and Methods}

2.1. Grains. Commercial regular yellow maize was purchased in a local market and cleaned with air aspiration (Seedburo Equipment Company) to remove foreign material or dockage. Then, the grains were milled with a $2 \mathrm{~mm}$ screen in a Wiley mill (Arthur Thomas, Philadelphia, PA, USA) to obtain the sample ground meal as the methodology applied by ChuckHernandez et al. [19].

2.2. Extrusion Process. The resulting maize meal was separated into two batches: one was stored and the other reserved for the extrusion trials. A twin extruder (BCTM-30 Buhler, Switzerland) with an $L / D=20$ was used to process the maize meal. The extruder operated at $250 \mathrm{rpm}$ and the last section of the extruder barrel was set at $120^{\circ} \mathrm{C}$. The screw configuration was selected to induce high levels of shear towards the end of the screws to induce starch gelatinization. Subsequently, the extrudates were collected and samples were placed into a dessicator. Then, extrudates were dried at $60^{\circ} \mathrm{C}$ in a convection oven and milled; the minimal drying was to control the final moisture before storage. Finally the chemical compositions of regular and extruded maize flours were determined.

2.3. Chemical Analyses. The chemical composition of the raw and extruded materials was determined by the following parameters: moisture, crude protein, crude fat, crude fiber, and ash. These assays were performed according to approved methods 44-15 A, 46-13, 30-20, 32-10, respectively [19]. In addition, the total starch content was measured according approved method 76-17 with a commercial kit of Megazyme [19]. Finally, the phenolic compounds assay was performed with the Folin reagent, subsequent to the addition of carbonate solution to the methanolic extracts [19].

2.4. Physical Analysis. The water absorption (WAI) and the water solubility (WSI) indexes were determined according to Anderson et al. [20]. Briefly, the ground and extruded meals were suspended in water at room temperature for 30 minutes, gently stirred, and then centrifuged at $3000 \times \mathrm{g}$ for 15 minutes. The supernatant was decanted into an evaporating dish. The WSI was expressed as the weight of dry solids in the supernatant, whereas the WAI was the weight of gel obtained after removal of the supernatant.

In addition, a particle size test was determined in a Rotap (Duratap Model DT168, Advantech Mfg., New Berlín, WI, USA). To perform the distribution size analysis, the maize or extruded flours were placed for $10 \mathrm{~min}$ in a Rotap equipped with a nest of coarse (mesh size number 30 and number 40), medium (mesh size number 60 and number 80 ), and fine (mesh number 100) sieves and a bottom collection pan [5].

2.5. Microorganisms and Preservation. The inoculum was prepared with the bacterium Z. mobilis ZM481 (ATCC 31823) grown in a culture medium referenced as RM ATCC 1341 (containing per liter of water adjusted to $\mathrm{pH} 6$ yeast extract, $10 \mathrm{~g}$; glucose, $20 \mathrm{~g}$; and $\mathrm{KH}_{2} \mathrm{PO}_{4}, 2.0 \mathrm{~g}$ ). The media and 
glucose were sterilized separately by autoclaving at $121^{\circ} \mathrm{C}$ for $15 \mathrm{~min}$. Finally, the glucose was mixed with the rest of the media components in sterile conditions (Labconco Model 36212, Kansas City, MI, USA).

The culture was maintained without mixing at $30^{\circ} \mathrm{C}$ in an incubator (VWR International, Model RF1575). The adequate phase growth to harvest the cells was considered in the $75 \%$ of the exponential phase with a count of $1.2 \times 10^{7}$ cells $/ \mathrm{mL}$ and the inoculum aliquots were spectrophotometrically monitored at $600 \mathrm{~nm}$ [5]. Following this growth condition, a volume between 7.5 and $10 \% \mathrm{v} / \mathrm{v}$ of the culture was inoculated to the batch fermentations [19]. The microorganism shows an accelerated growth between $10 \mathrm{~h}$ and $15 \mathrm{~h}$; this period of time was considered to collect the inoculum and to carry out the fermentation experiments.

\subsection{Fermentation Process}

2.6.1. Cereal Mashes Preparation. The raw and extruded maize meals were liquefied with thermoresistant $\alpha$-amylase (Liquozyme SC DS, Novozymes, Bagsvaerd, Denmark) according to previous investigations $[5,18]$. Then, hydrolyzates were saccharified with amyloglucosidase (Dextrozyme, Novozymes, Bagsvaerd, Denmark) in preparation for fermentation trials. The saccharification was performed at $60^{\circ} \mathrm{C}$ during $17 \mathrm{~h}$ in an incubator shaker (VWR International, Model RF1575) and the worts were diluted with distilled water to 12 or $20^{\circ} \mathrm{P}$ concentrations [21]. The gravity (expressed as ${ }^{\circ} \mathrm{P}$ ) was measured using a digital refractometer (CATAGO HRS 500, Bellevue, WA, USA).

2.6.2. Fermentation System. After the ${ }^{\circ}$ Plato ( $\left({ }^{\circ} \mathrm{P}\right.$, gravity) concentration was adjusted, the worts were pasteurized in a water bath and transferred to sterilized Erlenmeyer flasks without additional supplementation. Finally, worts were inoculated in sterile conditions (Labconco Model 36212, Kansas City, MI, USA) and incubated at $30^{\circ} \mathrm{C}$ without mixing for $72 \mathrm{~h}$ fermentation [21].

2.7. Analytical Methods. The $\mathrm{pH},{ }^{\circ} \mathrm{P}$, free-amino nitrogen (FAN) compounds, glucose, and ethanol were measured during fermentation. A potentiometer was used (Orion, Model 1230, Germany) for $\mathrm{pH}$ determinations in cereal mashes samples. In addition, the ${ }^{\circ} \mathrm{P}$ was measured directly from fermenting mashes placing a $50 \mu \mathrm{L}$ aliquot in a digital refractometer (CATAGO HRS 500, Bellevue, WA, USA). Both parameters were measured after the sample was collected from the fermentation system.

The collected samples were directly preserved at $-20^{\circ} \mathrm{C}$ for further colorimetric and chromatographic analyses. The amount of FAN generated during fermentation was determined by reaction with ninhydrin according to the Official Method 945.30 [19]. The glucose content was determined by HPLC-RI (Waters 2414, Milford, MA, USA) equipped with an ion-exchange column (Aminex HPX-87H, Biorad Hercules, CA, USA) as described previously by Chuck-Hernandez et al. [19]. Ethanol concentration was measured with Gas
Chromatography-FID equipped with a HP-Innowax $(30 \mathrm{~m} \times$ $0.53 \mathrm{~mm} \times 1 \mu \mathrm{m})$ column [21].

2.8. Experimental Design and Statistical Analysis. The research was conducted in two-level factorial design designed to evaluate two effects: type of feedstock (extruded or ground maize meals) and the concentration of wort (12 or $20^{\circ} \mathrm{P}$ ). The experiments were performed by triplicate. Statistical analysis was performed on the final $\mathrm{pH},{ }^{\circ} \mathrm{Plato}$, and FAN concentration using the software Minitab 16 (Minitab Inc., State College, PA). The chemical and physical properties were analyzed with descriptive statistics using means and standard deviations.

\section{Results and Discussions}

3.1. Chemical Composition. The chemical composition of feedstocks is presented in Table 1. Ground maize showed similar moisture, ash, crude fat, and protein content to the reported composition for corn meals in the literature [22]. The average amounts of protein, ash, and moisture for the extruded meal had similar values compared to its ground counterpart; however, a significant reduction of $36.66 \%$ of the phenolic compounds and $86.58 \%$ of the crude fat was found in the extruded treatment (Table 1). Wang and Ryu studied the changes induced by extrusion in corn phenolic compounds; they reported a decrease in total phenolics from 59.12 to $21.82 \mathrm{mg}$ GAE/100 g of dry basis when extrusion at $101.5^{\circ} \mathrm{C}$ was applied to raw material, because phenolic compounds are less resistant to heat and may alter natural properties [23] which present similarities to the results found in Table 1. Chuck-Hernandez et al. found that phenolics compounds did not affect ethanol production in cereal mashes [19]. Also, Carvalho et al. reported protein ranging from 6.15 to $8.04 \mathrm{~g} / 100 \mathrm{~g}$ and for crude fat from 0.57 to $0.79 / 100 \mathrm{~g}$ in extruded corn meals [11]. The protein $(8.09 \mathrm{~g} / 100 \mathrm{~g})$ content was close to the high-level value for the extruded meal whereas the crude fat $(0.42 \mathrm{~g} / 100 \mathrm{~g})$ was within reported values. Ethanol improvement could be partially explained in case of extruded material because of the physicochemical changes and the increase of the superficial area. Hernot et al. found a decrease in the organic matter concentrations after extrusion of native corn substrates, which suggests that high temperatures could breakdown thermolabile structures in crude fat [24]. The moisture was carefully measured; samples were collected in a desiccator after thermoplastic extrusion to avoid moisture loss for evaporation when the extruded samples reached room temperature and the moisture assay was performed.

Total starch values indicate a slight decrease after extrusion cooking and had a variation smaller than $9 \%$ when the raw and processed corn meals were compared, which suggests a similar trend to previous studies [25]. Changes in chemical properties suggest that during extrusion cooking the properties of maize meals could be modified because of polymer starch disintegration at $120^{\circ} \mathrm{C}$ [9].

3.2. Physical Properties. The experimental results shown in Table 1 suggest that thermoplastic extrusion changed 
TABLE 1: Physical and chemical properties of processed maize flour used for the fermentation worts.

\begin{tabular}{|c|c|c|}
\hline Parameters (\%) & Dried ground & Extruded $120^{\circ} \mathrm{C}$ \\
\hline \multicolumn{3}{|l|}{ Chemical composition } \\
\hline Moisture & $12.62 \pm 0.10$ & $12.90 \pm 0.10$ \\
\hline Ash content & $1.18 \pm 0.05$ & $1.18 \pm 0.02$ \\
\hline Protein & $8.84 \pm 0.50$ & $8.09 \pm 0.18$ \\
\hline Crude fat & $3.13 \pm 0.26$ & $0.42 \pm 0.08$ \\
\hline Total starch & $74.50 \pm 0.60$ & $71.77 \pm 1.32$ \\
\hline Crude fiber & $1.24 \pm 0.16$ & $2.67 \pm 0.12$ \\
\hline Phenolic compound ${ }^{\mathrm{a}}$ & $376.39 \pm 68.18$ & $238.37 \pm 25.19$ \\
\hline \multicolumn{3}{|l|}{ Physical properties } \\
\hline WAI & $2.82 \pm 0.19$ & $4.42 \pm 1.26$ \\
\hline WSI & $7.65 \pm 0.27$ & $17.54 \pm 6.68$ \\
\hline \multicolumn{3}{|l|}{ Particle size fraction ${ }^{\mathrm{b}}$} \\
\hline Coarse $(>420 \mathrm{~mm})$ & 61.68 & 37.74 \\
\hline Medium (149-420 mm) & 35.91 & 47.66 \\
\hline Fine $(<149 \mathrm{~mm})$ & 1.65 & 14.58 \\
\hline
\end{tabular}

${ }^{a}$ Expressed in $\mu$ g of ac gallic equivalents/dried gram.

${ }^{\mathrm{b}}$ Average values. Determined after grinding extruded and dried corn meals in a Wiley mill equipped with a $2 \mathrm{~mm}$ screen.

the distribution of particulates, water solubility (WSI), and water adsorption (WAI) indexes. The process increased the solubility of the extruded corn meal and enhanced the yield of finer particles after milling (Table 1). WAI measures the amount of water absorbed by starch and can be used as an index of gelatinization, whereas the WSI parameter is often used as an indicator of degradation of molecular components, measuring the amount of soluble components released from the starch after extrusion [7]. Both parameters reported higher experimental values for the extruded maize flour compared to the ground meals, which could be related to the degradation of starch and gelatinization, because of the high temperature during extrusion. Also, the dipolymers in the raw materials were subjected to protein denaturalization, starch glue formation, and plasticization of the complete volume [26]. In addition, the pressure change at the end of the die caused the starch to plasticize, which in conjunction with temperatures above $100^{\circ} \mathrm{C}$ produced water evaporation and expansion with the creation of a foam-like expanded product. In the extrusion process, the distribution of particle size was found to be a higher fraction oriented to the medium $(149-420 \mathrm{~nm})$ and small sizes $(<149 \mathrm{~nm})$, in comparison to the ground meals. In the case of the ground maize, the particle size distribution favored coarser fractions (Table 1). The particle size affects speed of enzyme hydrolysis and is also related to the bioavailability of sugars that the bacterium is able to use for its growth. During extrusion, the maize meal experienced thermomechanic stress conditions modifying its starch structure [6] which are known to impact the wort during fermentation.

3.3. The pH Profile of Maize Mashes during Fermentation. In fermentation, $\mathrm{pH}$ is an important factor because it affects the behavior of bacterium physiology, and a change in

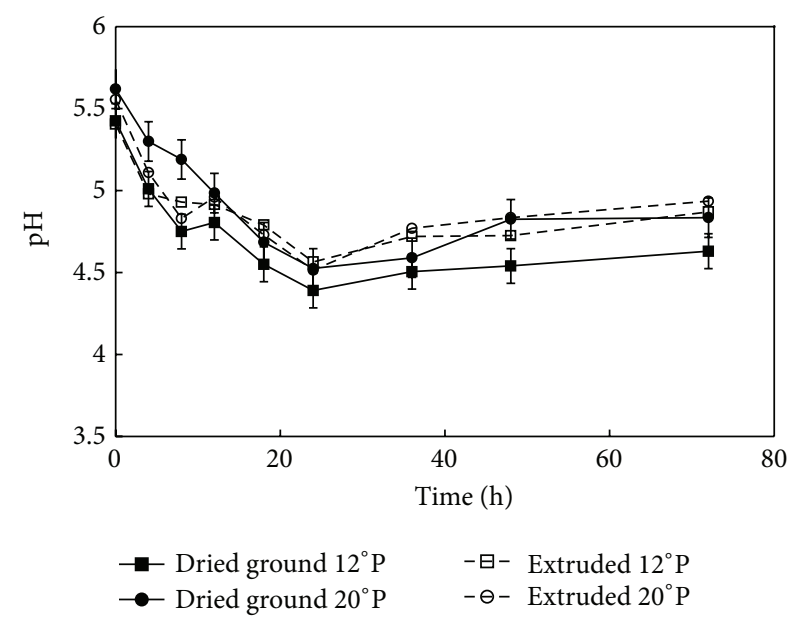

FIGURE 1: $\mathrm{pH}$ profile during fermentation of ground maize at 12 and $20^{\circ} \mathrm{P}$ and extruded maize at 12 and $20^{\circ} \mathrm{P}$ mashes by Zymomonas mobilis (ATCC 31822).

this parameter could decrease ethanol yield under certain circumstances [16, 17]. The $\mathrm{pH}$ of mashes was $4.75( \pm 0.15)$ during the 72 hours of $Z$. mobilis fermentation for all the treatments; this general trend can be observed in Figure 1. During fermentation, this bacterium can reduce the $\mathrm{pH}$ to 4.0-5.5, but if a $\mathrm{pH}$ further drops near 3.5, this indicates that a metabolic disorder may be related to contamination because of high accumulation of lactic and other organic acids [18]. In all of the cases, a maximum decrease of the $\mathrm{pH}$ of mashes was between the 10 and $25 \mathrm{~h}$ of fermentation, indicating the end of the process of conversion to ethanol [17].

An ANOVA was conducted to evaluate the type of feedstock (dried ground or extruded) and wort concentration $\left(12^{\circ} \mathrm{P}\right.$ or $\left.20^{\circ} \mathrm{P}\right)$ in the final $\mathrm{pH}$ in maize mashes after fermentation. This analysis shows that the type of feedstock had a significant influence in the final $\mathrm{pH}(P$ value $<0.05)$; however, the concentration was not found to have significant effect. The process type used for the feedstock over the $\mathrm{pH}$ could be related to the particle size of the corn meals, and the starch changes might affect the soluble sugars present in the wort during fermentation.

3.4. ${ }^{\circ}$ Plato Profile of Mashes during Fermentation. The ${ }^{\circ} \mathrm{P}$ profile of $Z$. mobilis is an indirect measurement and is shown in Figure 2. ${ }^{\circ}$ Plato monitoring is a preliminary indicator related to sugar content and can give valuable information about the performance of the microorganism during bioethanol production. Therefore, the Brix or Plato degrees are a reliable measurement for sugar, because of the ability of carbohydrates to affect the refraction index in the solution [27].

In the case of sweet sorghum, the available sugar percentage is significantly associated with Brix, reducing sugar content and $\mathrm{pH}$. Also, a linear correlation was found between ${ }^{\circ} \mathrm{P}$ and total sugar content with sweet sorghum in some studies [28]. In Figure 2, the maize worts showed decreased Brix content during $Z$. mobilis fermentation. 


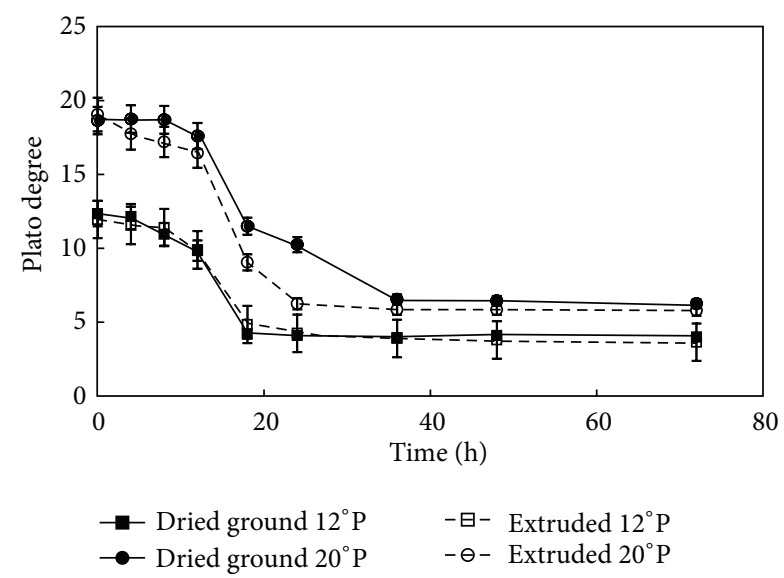

Figure 2: Plato degree profile during fermentation of ground maize at 12 and $20^{\circ} \mathrm{P}$ and extruded maize at 12 and $20^{\circ} \mathrm{P}$ mashes by Zymomonas mobilis (ATCC 31822).

A decrease between 10 and $25 \mathrm{~h}$ was observed in the fermentation treatments, which can be correlated with the $\mathrm{pH}$ decrease reported in the literature. Fermentation of starchy materials has been reported with ethanol production starting at $24 \mathrm{~h} \mathrm{[22];} \mathrm{the}{ }^{\circ} \mathrm{P}$ profile can help to estimate an approximate final value for the exponential stage after $25 \mathrm{~h}$ of fermentation with the preliminary information.

The type of process and initial concentration affected the final ${ }^{\circ} \mathrm{P}$ value. ANOVA analysis was applied to experimental data and the interaction between factors was found to be statistically significant. This result may suggest that extrusion as a process had an effect on the bioavailability and content of sugar in the maize meals.

Since the $20^{\circ} \mathrm{P}$ worts contained higher sugar concentration than the $12^{\circ} \mathrm{P}$ worts, a substrate inhibition by glucose could be present and this phenomenon could imply that concentrated worts might reduce process efficiency leaving residual sugar at the end of fermentation. The $12^{\circ} \mathrm{P}$ treatments had a higher sugar consumption leaving less residual sugar compared to the $20^{\circ} \mathrm{P}$ counterparts. A comparison of maize with other starchy substrates, such as sorghum and decorticated sorghum, has been reported extensively in the literature $[19,20]$.

3.5. FAN Consumption of Z. mobilis during Fermentation. In yeast fermentation, there are two important components that impact the overall process and efficiency: the initial sugars and the diversity of nitrogen compounds [14]. The nitrogen consumption of $Z$. mobilis is comparatively less relevant because its demand is lower compared to Saccharomyces cerevisiae [12]. For S. cerevisiae, a FAN content of $150 \mathrm{mg} / \mathrm{L}$ wort is considered as minimum to achieve good fermentation $[19,21,22]$.

The initial FAN content was lower in the evaluated worts, and this reduced amount of nutrients could modify the bacteria metabolism. Even though most Zymomonas strains are known to be autotrophic organisms, there are several reports in the literature of defined and minimum nutrients

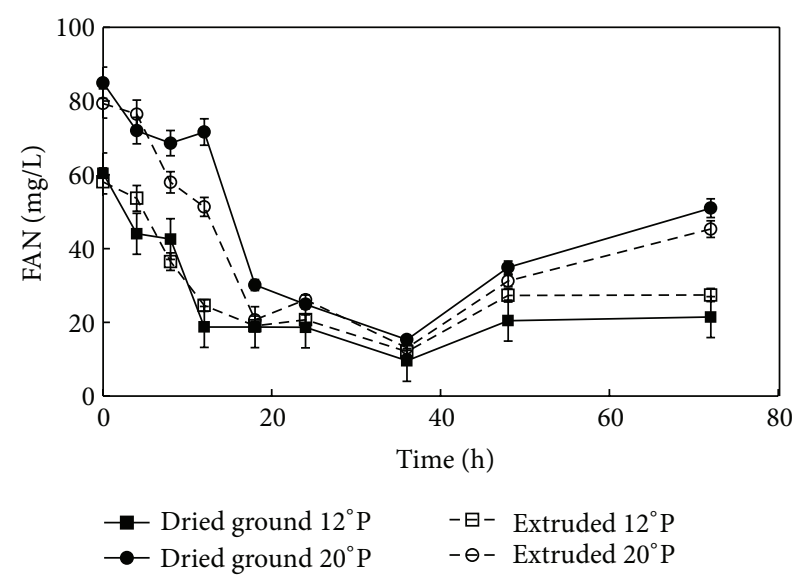

Figure 3: FAN (mg/L) concentration during fermentation of ground maize at 12 and $20^{\circ} \mathrm{P}$ and extruded maize at 12 and $20^{\circ} \mathrm{P}$ mashes by Zymomonas mobilis (ATCC 31822).

for Z. mobilis to achieve high performance fermentation [16]. Relatively little is understood concerning the specific influence on growth and assimilation of individual components of this bacterium, which requires lower nutrients in the media culture with respect to yeast in order to support its growth during fermentation [28].

In Figure 3, FAN consumption presents a similar trend in the four treatments. The major decrease in FAN compounds was observed between $8 \mathrm{~h}$ and $18 \mathrm{~h}$, which was found to have similarity with the time when the bacteria started higher glucose consumption (Figure 4). Whereas FAN concentration decreased $15.5 \%$ during the first $10 \mathrm{~h}$ fermentation in the $20^{\circ} \mathrm{P}$ mashes, $12^{\circ} \mathrm{P}$ mashes remained similar $(P>0.05)$. The total FAN consumption in the worts presented a lower value at $38 \mathrm{~h}$ in all treatments, and this behavior could be related to the death phase of the bacterial population. The increase of amino acids after the $40 \mathrm{~h}$ of process could be attributed to the autolysis of $Z$. mobilis and the hydrolysis of the initial nitrogen compounds into smaller peptides, which increased the FAN content during fermentation [28].

Process type did not affect the initial and final FAN contents in the corn meals, even though the FAN amount was not the optimum reported for other microorganisms; however for the bacterium the conditions were sufficient to fulfill its metabolism $[6,14]$. The demand of $Z$. mobilis for nitrogen compounds would be necessary to determine in future research.

3.6. Glucose Consumption in Maize Mashes during Fermentation. The comparison of the glucose profile as affected by the different treatments is shown in Figure 4 . The $20^{\circ} \mathrm{P}$ worts had a faster consumption of glucose compared to the $12^{\circ} \mathrm{P}$ counterparts; these experiments were performed in a batch system, to allow studying glucose generation and consumption after saccharification and fermentation, respectively. In the presence of glucose or fructose, Z. mobilis is able to grow, but glucose is preferred over fructose because of the specific kinetics of sugar uptake [14]. Figure 4 clearly 


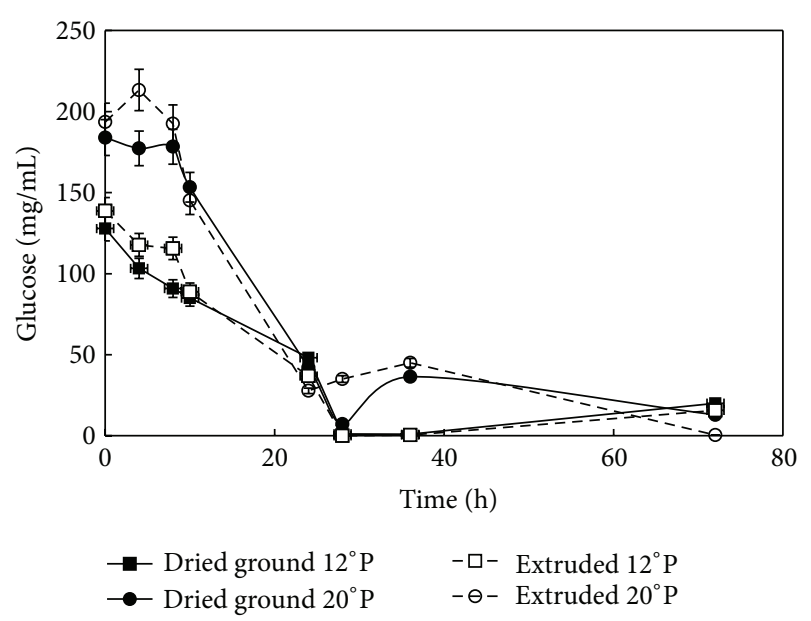

FIgURE 4: Glucose $(\mathrm{mg} / \mathrm{mL})$ consumption during fermentation of ground maize at 12 and $20^{\circ} \mathrm{P}$ and extruded maize at 12 and $20^{\circ} \mathrm{P}$ mashes Zymomonas mobilis (ATCC 31822).

depicts a decrease of glucose in the first $24 \mathrm{~h}$ of fermentation, which is similar to the $25 \mathrm{~h}$ period that Rogers et al. reported for a batch culture [16]. The rapid glucose transport rates between external and internal sugar concentrations may contribute to the osmotic adjustment $[6,14]$. In terms of the extrusion process, the $20^{\circ} \mathrm{P}$ extruded maize presented a steeper slope during the first $20 \mathrm{~h}$ of fermentation consumption compared to the $20^{\circ} \mathrm{P}$ ground raw maize. Also, the higher WSI observed in the extruded materials positively impacted glucose consumption between the $4 \mathrm{~h}$ and the $20 \mathrm{~h}$ due to their higher solubility.

Lawford reported $95 \%$ glucose consumption with a process based on corn starch hydrolyzed to contain 162-172 g glucose/L [29]. In the present study, the fermentation experiments were performed without mixing in order to avoid aeration. The aeration on growth and metabolism at high glucose concentration can yield inhibitors such as acetaldehyde. The isozyme alcohol dehydrogenase catalyzes in the microorganism the reduction of acetaldehyde to ethanol; however when fructose is not efficiently phosphorylated by fructokinase, both enzymes depend on the sugar in the culture. Therefore, the microorganism is less efficient on the ethanol batch fermentation [30].

3.7. Ethanol Production during Fermentation. Figure 5 clearly shows that independently of the type of treatment approximately $60 \%$ of the ethanol was produced during the first $20 \mathrm{~h}$ fermentation. This behavior could be the initial lag phase of the ethanol formation, which corresponded to the transformation phase of the bacterium from the lag to the exponential growth. A further increase of ethanol production occurred during the $20-30 \mathrm{~h}$ of fermentation similar to data previously reported by Perez-Carrillo et al. [6]. Results indicated that the proposed thermoplastic extrusion generated a feedstock more adequate for starch conversion and subsequent fermentation compared to the raw meal. The $12^{\circ} \mathrm{P}$ and $20^{\circ} \mathrm{P}$ mashes produced from the extruded
TABLE 2: Ethanol yield during fermentation of yellow maize with or without extrusion treatment at 20 or $12^{\circ} \mathrm{P}$ wort with Zymomonas mobilis (ATCC 31822).

\begin{tabular}{lccc}
\hline Treatment & ${ }^{\circ} \mathrm{P}$ & $\mathrm{L}(\mathrm{EtOH}) /$ flour $\mathrm{Kg}$ & $\mathrm{L}(\mathrm{EtOH}) /$ starch $\mathrm{Kg}$ \\
\hline \multirow{2}{*}{ Ground maize } & 12 & $0.272 \pm 0.016$ & $0.387 \pm 0.027$ \\
& 20 & $0.305 \pm 0.011$ & $0.432 \pm 0.011$ \\
\hline \multirow{2}{*}{ Extruded maize } & 12 & $0.312 \pm 0.020$ & $0.437 \pm 0.042$ \\
& 20 & $0.330 \pm 0.100$ & $0.468 \pm 0.014$ \\
\hline
\end{tabular}

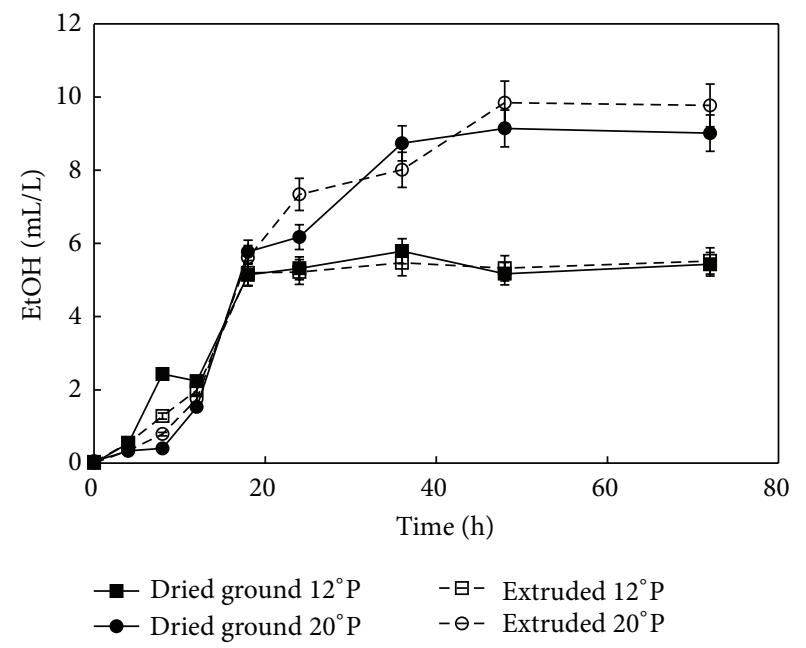

Figure 5: Ethanol $(\mathrm{mL} / \mathrm{L})$ production during fermentation of ground maize at 12 and $20^{\circ} \mathrm{P}$ and extruded maize at 12 and $20^{\circ} \mathrm{P}$ mashes by Zymomonas mobilis (ATCC 31822).

feedstock yielded $12.2 \%$ and $8.4 \%$ more ethanol compared to the uncooked counterparts. Ethanol production was higher in the fermentation systems with $20^{\circ} \mathrm{P}$ compared to worts with $12^{\circ} \mathrm{P}$. The high gravity regular and extruded worts yielded $10.8 \%$ and $6.1 \%$ more ethanol compared to the $12^{\circ} \mathrm{P}$ counterparts (Table 2) which allows less water consumption during the process. The combination of extrusion mashes show improvements in Z. mobilis fermentation until 20.93\% compared to the uncooked mashes; the comparative chart is presented in Table 2. In previous work [6] reported ethanol yield at $20^{\circ} \mathrm{P}$ of $0.27 \mathrm{~L} /$ ground grain $\mathrm{kg}$, similar to value obtained in this work at $13^{\circ} \mathrm{P}$ with uncooked mashes. This study provides a combination that opens a possibility of reducing water consumption and better use of existing fermentation reactors.

\section{Conclusions}

Thermoplastic extrusion improved glucose consumption and bioavailability throughout fermentation especially for high gravity worts. This effect can be related to the finer particle size, solubility, and chemical changes generated during extrusion of maize meals especially in terms of starch gelatinization. Extruded treatments enhanced ethanol concentration by $10.19 \%$ compared to ground treatments which positively impact fermentation. $Z$. mobilis showed synergism with raw 
and extruded $20^{\circ} \mathrm{P}$ mashes yielding $10.8 \%$ and $6.1 \%$ more ethanol compared to the $12^{\circ} \mathrm{P}$ counterparts. This research demonstrates that the combination of extrusion cooking and fermentation of $20^{\circ} \mathrm{P}$ mashes is advantageous from the ethanol and efficiency viewpoints.

\section{Conflict of Interests}

The authors declare that there is no conflict of interests regarding the publication of this paper.

\section{Acknowledgments}

Mayeli Peralta Contreras wants to express her gratitude to CONACYT for the graduate student scholarship and to the Research Chair CAT 151 from Tecnologico de Monterrey, Campus Monterrey for funding the present research.

\section{References}

[1] M. O. S. Dias, A. V. Ensinas, S. A. Nebra, R. Maciel Filho, C. E. V. Rossell, and M. R. W. Maciel, "Production of bioethanol and other bio-based materials from sugarcane bagasse: integration to conventional bioethanol production process," Chemical Engineering Research and Design, vol. 87, no. 9, pp. 1206-1216, 2009.

[2] D. Antoni, V. V. Zverlov, and W. H. Schwarz, "Biofuels from microbes," Applied Microbiology and Biotechnology, vol. 77, no. 1, pp. 23-35, 2007.

[3] M. Kumar, J. Pucci, J. Shetty, G. Chotani, and K. Sanford, "Chapter 3. Biocatalytic conversion of granular starch to industrial chemicals," in Industrial Application of Enzymes on Carbohydrate-Based Material, vol. 972 of ACS Symposium Series, pp. 32-45.

[4] R. J. Bothast and M. A. Schlicher, "Biotechnological processes for conversion of corn into ethanol," Applied Microbiology and Biotechnology, vol. 67, no. 1, pp. 19-25, 2005.

[5] C. Chuck-Hernandez, E. Perez-Carrillo, and S. O. SernaSaldivar, "Production of bioethanol from steam-flaked sorghum and maize," Journal of Cereal Science, vol. 50, no. 1, pp. 131-137, 2009.

[6] E. Perez-Carrillo, M. L. Cortes-Callejas, L. E. Sabillon-Galeas et al., "Detrimental effect of increasing sugar concentrations on ethanol production from maize or decorticated sorghum mashes fermented with Saccharomyces cerevisiae or Zymomonas mobilis," Biotechnology Letters, vol. 33, no. 2, pp. 301-307, 2011.

[7] Q.-B. Ding, P. Ainsworth, A. Plunkett, G. Tucker, and H. Marson, "The effect of extrusion conditions on the functional and physical properties of wheat-based expanded snacks," Journal of Food Engineering, vol. 73, no. 2, pp. 142-148, 2006.

[8] M. Majzoobi and A. Farahnaky, "Comparison of the effects of extrusion cooking on some cereal starches," International Journal of Food Engineering, vol. 6, no. 3, article 2, 2010.

[9] T. Baks, F. H. J. Kappen, A. E. M. Janssen, and R. M. Boom, "Towards an optimal process for gelatinisation and hydrolysis of highly concentrated starch-water mixtures with alpha-amylase from B. licheniformis," Journal of Cereal Science, vol. 47, no. 2, pp. 214-225, 2008.

[10] W. Bindzus, G. Fayard, B. van Lengerich, and F. Meuser, "Description of extrudate characteristics in relation to the shear stress of plasticised starches determined in-line," StarchStärke, vol. 54, no. 6, pp. 252-259, 2002.

[11] C. W. P. Carvalho, C. Y. Takeiti, C. I. Onwulata, and L. O. Pordesimo, "Relative effect of particle size on the physical properties of corn meal extrudates: effect of particle size on the extrusion of corn meal," Journal of Food Engineering, vol. 98, no. 1, pp. 103-109, 2010.

[12] K. Naidu, V. Singh, D. B. Johnston, K. D. Rausch, and M. E. Tumbleson, "Effects of ground corn particle size on ethanol yield and thin stillage soluble solids," Cereal Chemistry, vol. 84, no. 1, pp. 6-9, 2007.

[13] F. W. Bai, W. A. Anderson, and M. Moo-Young, "Ethanol fermentation technologies from sugar and starch feedstocks," Biotechnology Advances, vol. 26, no. 1, pp. 89-105, 2008.

[14] Y. Lin and S. Tanaka, "Ethanol fermentation from biomass resources: current state and prospects," Applied Microbiology and Biotechnology, vol. 69, no. 6, pp. 627-642, 2006.

[15] H. Kitagaki, Y. Araki, K. Funato, and H. Shimoi, "Ethanolinduced death in yeast exhibits features of apoptosis mediated by mitochondrial fission pathway," FEBS Letters, vol. 581, no. 16, pp. 2935-2942, 2007.

[16] P. L. Rogers, Y. J. Jeon, K. J. Lee, and H. G. Lawford, "Zymomonas mobilis for fuel ethanol and higher value products," Advances in Biochemical Engineering/Biotechnology, vol. 108, pp. 263-288, 2007.

[17] R. A. Moreau, M. J. Powell, W. F. Fett, and B. D. Whitaker, "The effect of ethanol and oxygen on the growth of Zymomonas mobilis and the levels of hopanoids and other membrane lipids," Current Microbiology, vol. 35, no. 2, pp. 124-128, 1997.

[18] E. Pérez-Carrillo, M. L. Cortés-Callejas, L. E. Sabillón-Galeas et al., "Detrimental effect of increasing sugar concentrations on ethanol production from maize or decorticated sorghum mashes fermented with Saccharomyces cerevisiae or Zymomonas mobilis," Biotechnology Letters, vol. 33, no. 2, pp. 301-307, 2011.

[19] C. Chuck-Hernandez, M. Peralta-Contreras, G. BandoCarranza et al., "Bioconversion into ethanol of decorticated red sorghum (Sorghum bicolor L. Moench) supplemented with its phenolic extract or spent bran," Biotechnology Letters, vol. 34, no. 1, pp. 97-102, 2012.

[20] R. A. Anderson, H. F. Conway, V. F. Peifer, and E. I. Griffin, "Roll and extrusion-cooking of grain sorghum grits," Cereal Science Today, vol. 14, no. 11, pp. 372-376, 1969.

[21] E. Perez-Carrillo, S. O. Serna-Saldivar, C. Chuck-Hernandez, and M. L. Cortes-Callejas, "Addition of protease during starch liquefaction affects free amino nitrogen, fusel alcohols and ethanol production of fermented maize and whole and decorticated sorghum mashes," Biochemical Engineering Journal, vol. 67, pp. 1-9, 2012.

[22] M. Peralta-Contreras, C. Chuck-Hernandez, E. Perez-Carrillo et al., "Fate of free amino nitrogen during liquefaction and yeast fermentation of maize and sorghums differing in endosperm texture," Food and Bioproducts Processing, vol. 91, no. 1, pp. 4653, 2013.

[23] Y.-Y. Wang and G.-H. Ryu, "Physicochemical and antioxidant properties of extruded corn grits with corn fiber by $\mathrm{CO}_{2}$ injection extrusion process," Journal of Cereal Science, vol. 58, no. 1, pp. 110-116, 2013.

[24] D. C. Hernot, T. W. Boileau, L. L. Bauer, K. S. Swanson, and G. C. Fahey Jr., "In vitro digestion characteristics of unprocessed and processed whole grains and their components," Journal of Agricultural and Food Chemistry, vol. 56, no. 22, pp. 1072110726, 2008. 
[25] F. Y. Ayadi, K. A. Rosentrater, K. Muthukumarappan, and M. L. Brown, "Twin-screw extrusion processing of distillers dried grains with solubles (DDGS)-based yellow perch (Perca flavescens) feeds," Food and Bioprocess Technology, vol. 5, no. 5, pp. 1963-1978, 2012.

[26] H. Erten, H. Tanguler, and H. Cakiroz, "The effect of pitching rate on fermentation and flavour compounds in high gravity brewing," Journal of the Institute of Brewing, vol. 113, no. 1, pp. 75-79, 2007.

[27] S. Audilakshmi, A. K. Mall, M. Swarnalatha, and N. Seetharama, "Inheritance of sugar concentration in stalk (brix), sucrose content, stalk and juice yield in sorghum," Biomass and Bioenergy, vol. 34, no. 6, pp. 813-820, 2010.

[28] B.-H. Um and T. R. Hanley, "A comparison of simple rheological parameters and simulation data for Zymomonas mobilis fermentation broths with high substrate loading in a $3-\mathrm{L}$ bioreactor," Applied Biochemistry and Biotechnology, vol. 145, no. 1-3, pp. 29-38, 2008.

[29] H. G. Lawford, "Corn steep liquor as a cost-effective nutrition adjunct in high-performance Zymomonas ethanol fermentations," Applied Biochemistry and Biotechnology, vol. 63-65, no. 1, pp. 287-304, 1997.

[30] M. S. Krishnan, F. Taylor, B. H. Davison, and N. P. Nghiem, "Economic analysis of fuel ethanol production from corn starch using fluidized-bed bioreactors," Bioresource Technology, vol. 75, no. 2, pp. 99-105, 2000. 

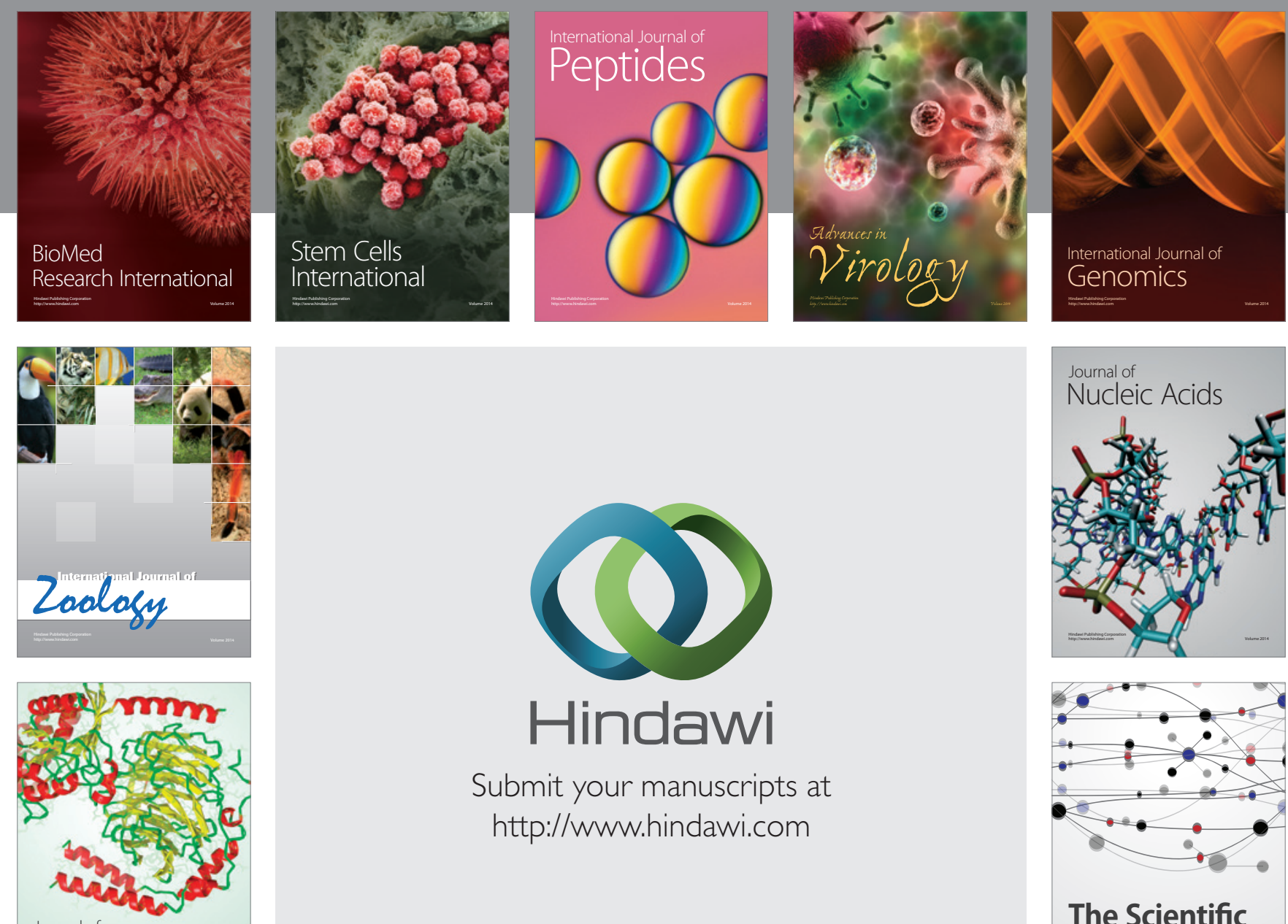

Submit your manuscripts at

http://www.hindawi.com

Journal of
Signal Transduction
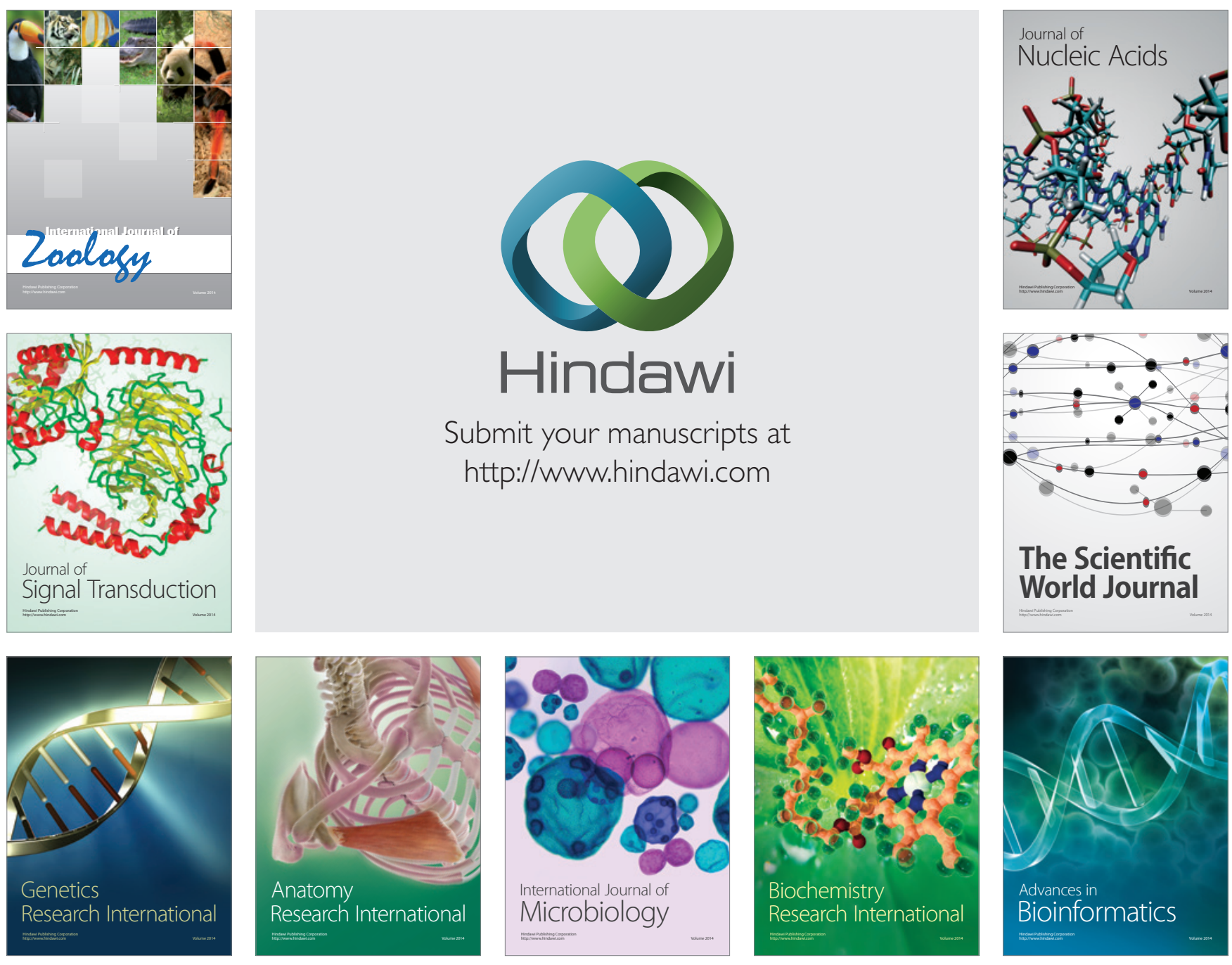

The Scientific World Journal
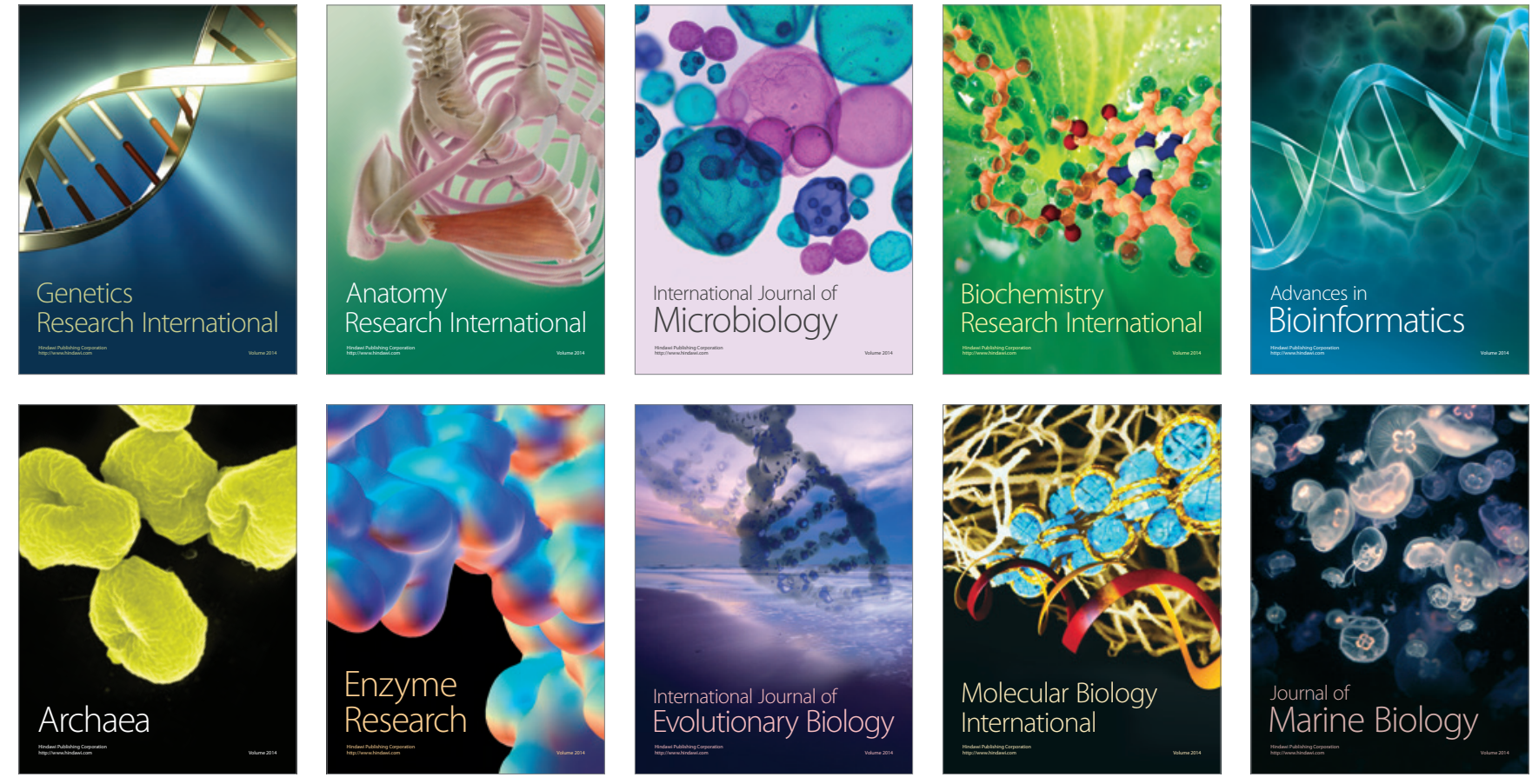